\title{
Digital Radiography of the Musculoskeletal System: The Optimal Image
}

\author{
Matthew Freedman and Dot Steller
}

\begin{abstract}
Digital radiography (DR) is replacing screen-film (SF) radiography for musculoskeletal examinations in our institution. After an iterative process of image quality improvement, our DR images are now preferred to SF images, and we have detailed our current optimized settings for the Fuji 9000 (Fuji Medical Systems, Tokyo, Japan). DR offers the advantages of improved contrast resolution, adjustable image contrast, the ability to reprocess the image, and the ease of transferring the image to an image management and communication system (IMAC).

Copyright 1995 by W.B. Saunders Company
\end{abstract}

KEY WORDS: musculoskeletal digital radiography.

$\mathbf{D}^{1}$ IGITAL RADIOGRAPHY (DR) of the musculoskeletal system is generally considered an adequate substitute for conventional screen-film (SF) radiography and has been widely used in the medical diagnostic imaging system (MDIS) program and elsewhere. ${ }^{1}$ Concern has been expressed regarding whether the resolution is adequate for all purposes with particular concern expressed regarding its use in the detection of subtle fractures and the subperiosteal resorption of hyperparathyroidism..$^{2-4}$

Previous studies have relied on image-processing parameter settings producing a film-screenlike image. ${ }^{2,5}$ Our initial experience in evaluating digital radiography systems showed to our satisfaction that the recommendations for image processing provided by the manufacturers of such devices did not always result in an optimal image for interpretation. We have found that the Fuji 9000 performs far better with the manufacturer's recommended settings than did our AC-1 and have found only minor deviations from their recommendations to our current practice. We have reported previously on methods of image optimization for musculoskeletal digital radiography ${ }^{6-8}$ and in this article will be giving examples of our current practice. $\mathrm{Al}$ though others ${ }^{2,3}$ have used film-like images without contrast enhancement, we find that subtle fractures can lie in regions of low contrast and that contrast enhancement is indeed of benefit in selected cases. Such low-contrast areas occur where a fracture is to be traced through a bone (rather than on its surface) or when avulsion fragments are very small and, therefore, are not very radiodense.

Our group considers digital radiography of the musculoskeletal system superior to conventional radiography because it provides better conspicuity of abnormalities, equivalent resolution to the screen-film system we had been using, advantages in providing a variable latitude of contrast and the capability of image reprocessing from the same original data set. We have almost completely replaced conventional radiography with digital radiography in the hospital and emergency department, and we plan to replace conventional screen-film radiography with digital radiography in our outpatient unit within a year. Although it is still possible to obtain higher-resolution images on screen-film systems with higher exposures than we normally use, for the exposure level we use in our 100 -speed system, we consider the image quality of DR superior.

\section{ASSURING THE QUALITY IMAGE}

Achieving high-quality images with a DR system involves more than simply replacing $\mathrm{SF}$ with DR. There are important differences in the two systems that require special training of technologists using the system. Choice of the smallest possible imaging plate and the appropriate use of high-resolution imaging plates is essential if high-quality images are to result. Proper exposure and the proper use of collimation are essential.

The image-processing algorithms must be adjusted to provide maximal information. We have previously described the optimization pro-

From the Divisions of Musculoskeletal Radiology and Imaging Science and Information Systems, Department of Radiology, Georgetown University Hospital, Washington, DC.

Address reprint requests to Matthew Freedman, MD, MBA, Department of Radiology, Georgetown University Hospital, 3800 Reservoir Rd NW, Washington, DC 20007.

Copyright $\odot 1995$ by W.B. Saunders Company 0897-1889/95/0801-1010\$3.00/0 
Table 1. Image Processing Settings for the Fuji 9000

\begin{tabular}{|c|c|c|c|c|c|c|c|}
\hline \multirow{2}{*}{$\begin{array}{c}\text { Anatomic } \\
\text { Region }\end{array}$} & \multicolumn{7}{|c|}{ Parameter Values } \\
\hline & GA & GT & GC & GS & RN & RT & RE \\
\hline \multicolumn{8}{|l|}{$\mathrm{TIB} / \mathrm{FIB}$} \\
\hline Fuji & 0.8 & 0 & 0.6 & 0.4 & 5 & $\mathrm{~F}$ & 1.0 \\
\hline \multicolumn{8}{|l|}{ Georgetown } \\
\hline \multicolumn{8}{|l|}{ Ankle } \\
\hline Fuji & 0.8 & 0 & 0.6 & 0.4 & 5 & $F$ & 1.0 \\
\hline Georgetown & 1.1 & $\mathrm{~N}$ & 0.6 & -.07 & 5 & $F$ & 0.5 \\
\hline \multicolumn{8}{|l|}{ Foot } \\
\hline Fuji & 0.8 & 0 & 0.6 & 0.3 & 5 & $T$ & 0.5 \\
\hline Georgetown & 1.2 & $\mathrm{~N}$ & 0.6 & -.05 & 7 & $T$ & 0.5 \\
\hline \multicolumn{8}{|l|}{ C-spine } \\
\hline Fuji & 1.1 & $\mathrm{~F}$ & 0.6 & 0.5 & 5 & $P$ & 0.5 \\
\hline \multicolumn{8}{|l|}{ Georgetown } \\
\hline \multicolumn{8}{|l|}{ T-spine } \\
\hline Fuji & 1.1 & G & 0.9 & 0.6 & 5 & $\mathrm{~T}$ & 1.0 \\
\hline \multicolumn{8}{|l|}{ Georgetown } \\
\hline \multicolumn{8}{|l|}{ L-spine } \\
\hline Fuji & 1.1 & 0 & 0.9 & 0.4 & 5 & $\mathrm{~T}$ & 1.0 \\
\hline Georgetown & 1.1 & $\mathrm{~J}$ & 0.9 & 0.4 & 9 & $\mathrm{~T}$ & 1.0 \\
\hline Toes & & & & & & & \\
\hline Fuji & 0.9 & 0 & 0.6 & 0 & 5 & $T$ & 0.5 \\
\hline Georgetown & & & & & & & \\
\hline Sinus & & & & & & & \\
\hline Fuji & 1.2 & G & 0.9 & 0.3 & 6 & $\mathbf{T}$ & 0.5 \\
\hline Georgetown & & & & & & & \\
\hline Facial bones & & & & & & & \\
\hline Fuji & 1.2 & G & 0.9 & 0.3 & 6 & $T$ & 0.5 \\
\hline Georgetown & We use & orithr & was o & sinus $c$ & & & \\
\hline Zygomatic arch & & & & & & & \\
\hline Fuji & 1.0 & G & 2.0 & 0.3 & 5 & 0 & 0.5 \\
\hline Georgetown & & & & & & & \\
\hline Breast/breast & & & & & & & \\
\hline Fujit & 1.2 & G & 8.6 & 0.3 & 5 & $P$ & 1.0 \\
\hline Georgetown & & & & & & & \\
\hline Finger & & & & & & & \\
\hline Fuji & 0.9 & 0 & 0.6 & 0.3 & 5 & $\mathrm{~T}$ & 0.5 \\
\hline Georgetown & & & & & & & \\
\hline Hand & & & & & & & \\
\hline Fuji & 0.9 & 0 & 0.6 & 0.5 & 5 & $\mathrm{~T}$ & 0.5 \\
\hline Georgetown & & & & & & & \\
\hline Wrist & & & & & & & \\
\hline Fuji & 0.8 & 0 & 0.6 & 0.2 & 5 & $T$ & 1.0 \\
\hline Georgetown & & & & & & & \\
\hline Forearm & & & & & & & \\
\hline Fuji & 0.8 & 0 & 0.6 & 0.2 & 5 & $T$ & 1.0 \\
\hline Georgetown & 1.0 & 0 & 0.6 & 0.2 & 5 & $\mathrm{~T}$ & 0.5 \\
\hline Elbow & & & & & & & \\
\hline Fuji & 0.8 & 0 & 0.6 & 0.4 & 5 & $\mathrm{~T}$ & 1.0 \\
\hline Georgetown & & & & & & & \\
\hline Shoulder & & & & & & & \\
\hline Fuji & 1.2 & G & 0.6 & 0.1 & 5 & $T$ & 1.0 \\
\hline Georgetown & & & & & & & \\
\hline Upper ribs & & & & & & & \\
\hline Fuji & 0.7 & 0 & 1.6 & -.2 & 5 & $\mathrm{R}$ & 1.5 \\
\hline Georgetown & 0.8 & 0 & 1.6 & 0 & 5 & $R$ & 1.0 \\
\hline Pelvis & & & & & & & \\
\hline Fuji & 0.9 & 0 & 0.6 & 0.2 & 4 & $T$ & 1.0 \\
\hline Georgetown & & & & & & & \\
\hline Нip & & & & & & & \\
\hline Fuji & 1.3 & 0 & 1.6 & 0.4 & 5 & $\mathbf{R}$ & 0.5 \\
\hline Georgetown & & & & & & & \\
\hline Femur & & & & & & & \\
\hline Fuji & 0.8 & 0 & 0.6 & 0.5 & 5 & $F$ & 0.5 \\
\hline Georgetown & & & & & & & \\
\hline Knee & & & & & & & \\
\hline Fuji & 0.8 & 0 & 0.6 & 0.5 & 5 & $F$ & 0.5 \\
\hline Georgetown & 1.0 & 0 & 0.6 & 0.5 & 5 & $F$ & 0.5 \\
\hline
\end{tabular}

This lists the Fuji recommended image-processing settings and the Georgetown optimized image-processing settings for examinations of the musculoskeletal system. The settings are optimized for the Fuji 9000. 


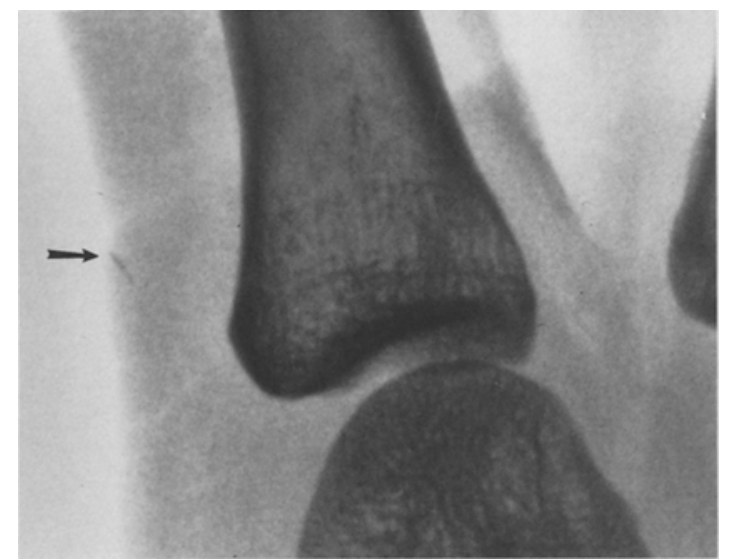

Fig 1. A small fragment of glass (arrow) lies within the soft tissues of the finger.

cedure that we follow. ${ }^{4-6}$ Briefly, we initially obtain images on both SF and DR systems in matched pairs. The DR images are processed by a series of carefully chosen parameter settings to produce multiple images from each data set. A team of two or three radiologists then reviews the images grouped by anatomic region. Records are kept of preferences and also of those algorithms that provided full information versus those that conceal information. The process is

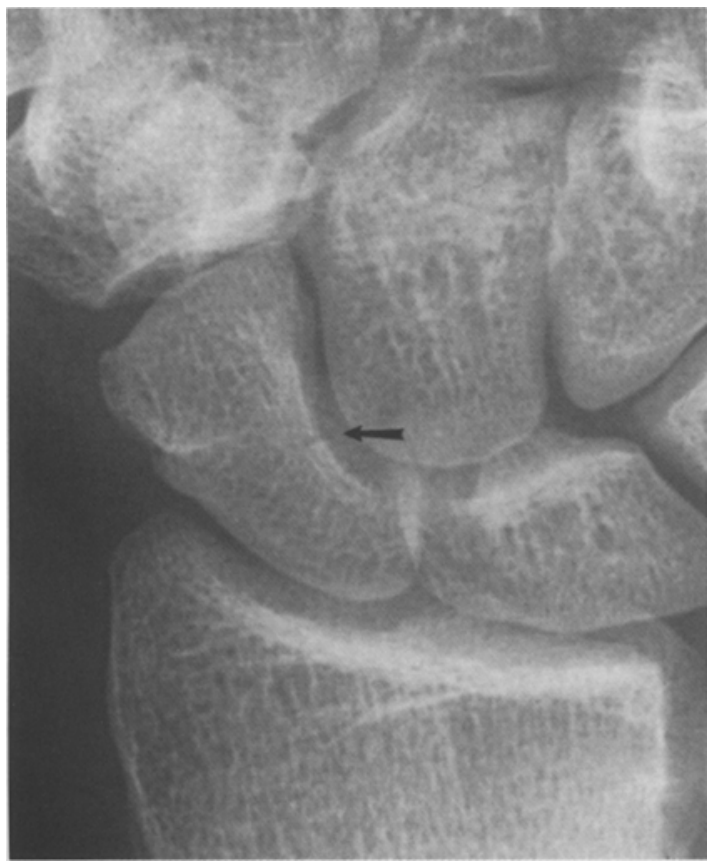

Fig 2. A subtle scaphoid fracture is present (arrow). $\mathbf{G}=$ $0.8,0,0.6,+0.2 ; A=7, V, 5.0$
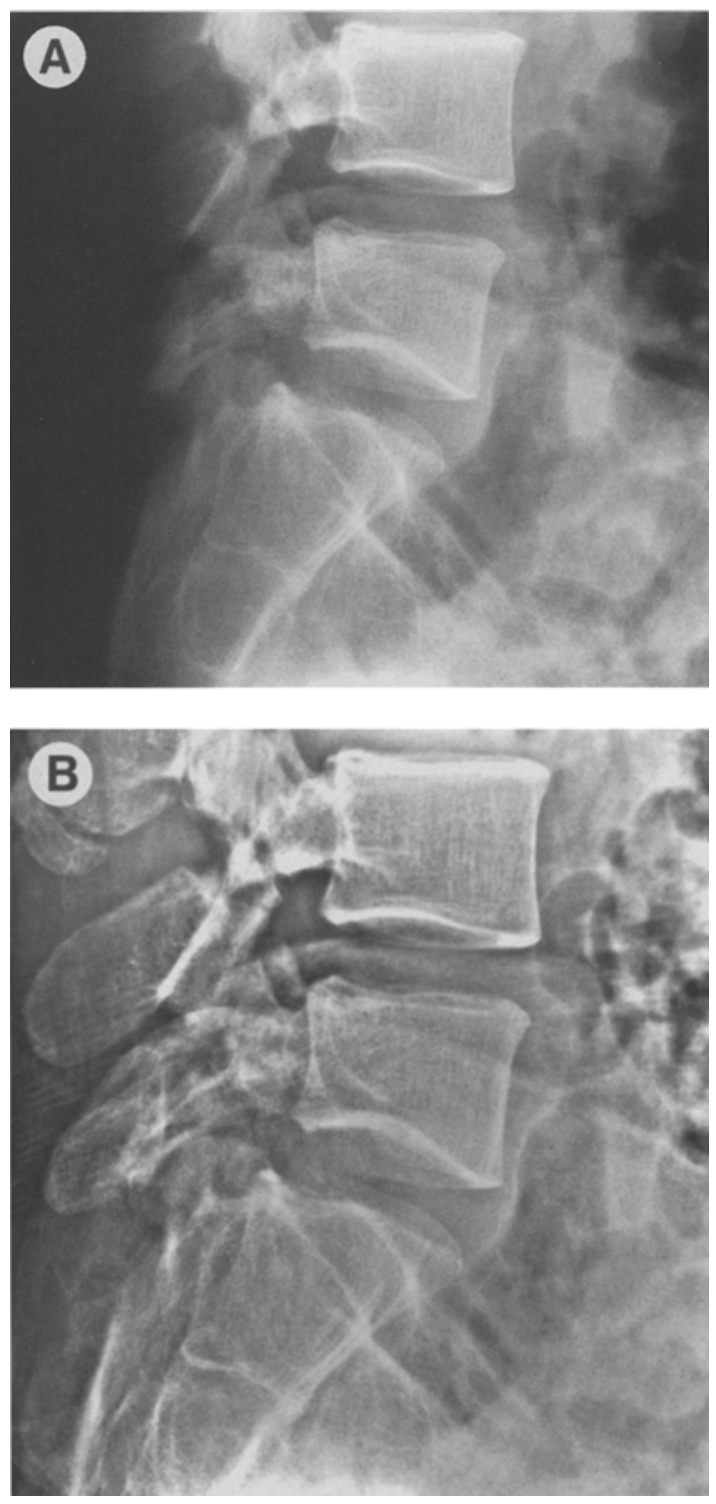

Fig 3. Lateral lumbar spine shows spondylolisthesis and spondylolysis. (B) shows the posterior elements to better advantage. (A) $\mathrm{L}=2.3 ; \mathrm{G}=1.1, \mathrm{~J}, 0.9,+0.4 ; R=9, \mathrm{~T}, 1.0$. (B) $L=2.3 ; G=0.6, J, 0.9,+0.4 ; R=2, T, 5.0$.

repeated until image quality for each body part is considered relatively well optimized. Table 1 indicates our current recommendations for image processing on the Fuji 9000 based on approximately 10,000 spine and extremity images obtained on the Fuji 9000 and 5000 images from the AC-1. Optimal parameter settings for the Fuji 9000 are not directly transferable to the $\mathrm{AC}-1$. The differences between the AC-1 and Fuji 9000 settings result (we believe) from the 
Table 2. Techniques For Different Anatomical Regions (average-size patient)

\begin{tabular}{|c|c|c|c|c|c|c|c|c|c|}
\hline Anatomy & $k \vee p$ & $\mathrm{~mA}$ & sec & mAs & $\begin{array}{c}\text { SDD } \\
\text { (inches) }\end{array}$ & Bucky & Tabletop & $\begin{array}{c}\text { AFS } \\
\text { (large) }\end{array}$ & $\begin{array}{c}\text { AFS } \\
\text { (small) }\end{array}$ \\
\hline Skull & 73 & 320 & .1 & 32 & 32 & $x$ & & & $x$ \\
\hline Cervical spine & 73 & 250 & .1 & 25 & 72 & $x$ & & $x$ & \\
\hline Chest & 125 & 320 & .0125 & 4 & 72 & $\mathrm{x}$ & & $\mathrm{x}$ & \\
\hline Abdomen (KUB) & 73 & 320 & .1 & 32 & 40 & $\mathrm{x}$ & & $x$ & \\
\hline Lateral lumbar spine & 85 & 320 & .15 & 50 & 40 & $x$ & & $x$ & \\
\hline Femur & 73 & 250 & .1 & 25 & 40 & $x$ & & $x$ & \\
\hline Knee & 66 & 250 & .025 & 6.3 & 40 & $x$ & & $x$ & \\
\hline Ankle* & 63 & 250 & .02 & 5 & 40 & & $x$ & & $x$ \\
\hline Foot* & 63 & 250 & .02 & 5 & 40 & & $x$ & & $x$ \\
\hline Shoulder & 70 & 250 & .04 & 10 & 40 & $x$ & & & $x$ \\
\hline Elbow* & 63 & 250 & .025 & 6.3 & 40 & & $x$ & & $x$ \\
\hline Wrist* & 60 & 250 & .02 & 5 & 40 & & $x$ & & $x$ \\
\hline Hand* & 60 & 250 & .02 & 5 & 40 & & $x$ & & $x$ \\
\hline
\end{tabular}

Abbreviations: SDD, source-to-detector distance; AFS, focal spot size.

*External cassette (no grid), HR plate.

improved signal to noise ratio in the Fuji 9000 and the improved laser printer used with it. Our optimized settings differ only slightly from those recommended by the manufacturer. On the $\mathrm{AC}-1$, we had more differences with the manufacturer's recommendation. We believe the difference is caused by the higher contrast seen on the LP414N laser imager (Fuji) supplied with our Fuji 9000.

\section{ADVANTAGES OF DR OF THE MUSCULOSKELETAL SYSTEM}

Based on our experience, we consider the main advantages of DR of the musculoskeletal system to be high resolution, an adjustable range of contrast and brightness, the ability to reprocess image to obtain additional information, and the use of DR as an entry point into an image management and communication system (IMAC).

\section{RESOLUTION}

Achieving adequate resolution depends on the use of imaging plates of the correct size and the use of the high resolution imaging plates for all hands, wrists, elbows, ankles, and feet. The high-resolution imaging plates provide approxi-
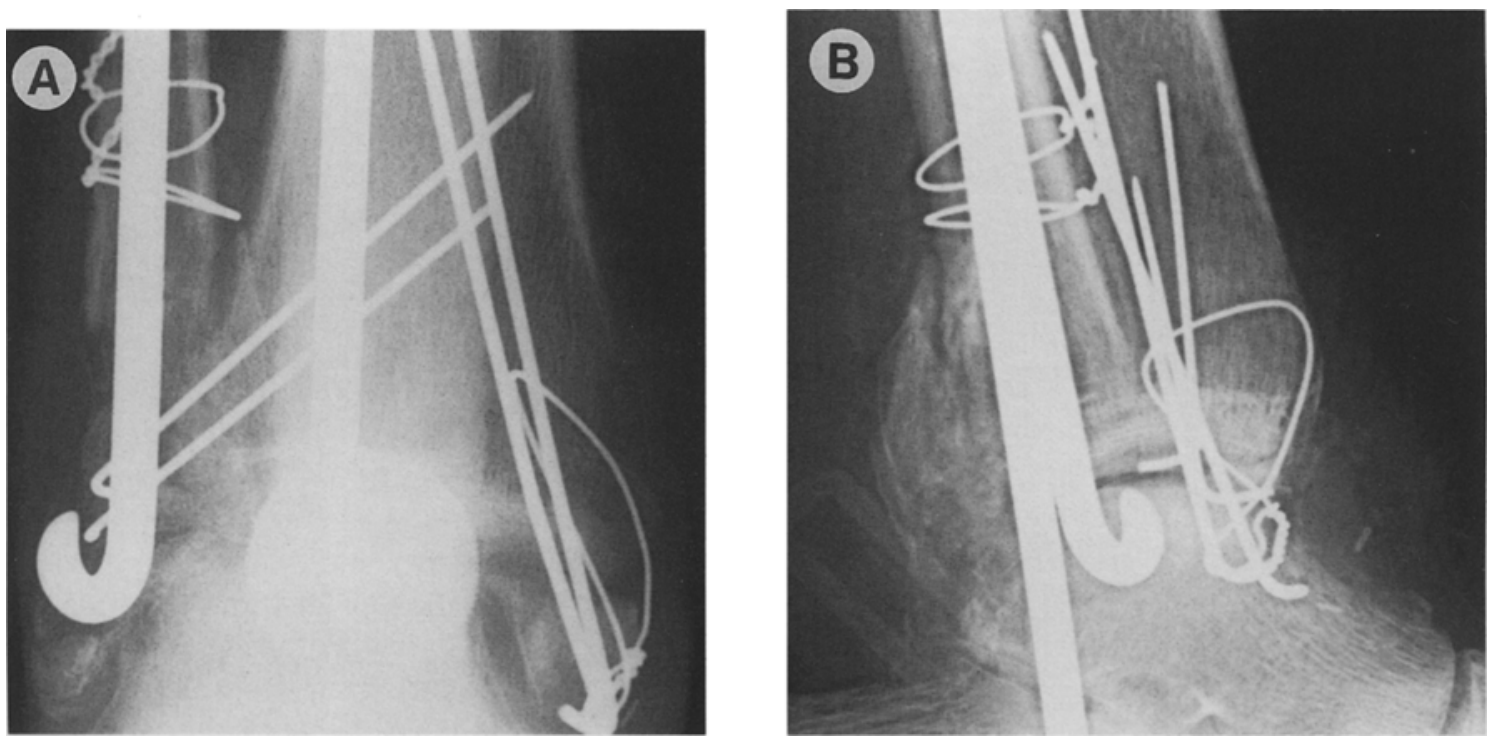

Fig 4. Ankle fracture. The smaller kernel size in (A) causes less of a metal edge artifact than the larger kernal size in $(B)$. (A) $G=1.1$; $J, 0.6,+0.2 ; R=8 ; F, 1.0$. (B) $G=1.1 ; N, 0.6,-0.07 ; R=5 ; F, 1.0$ 

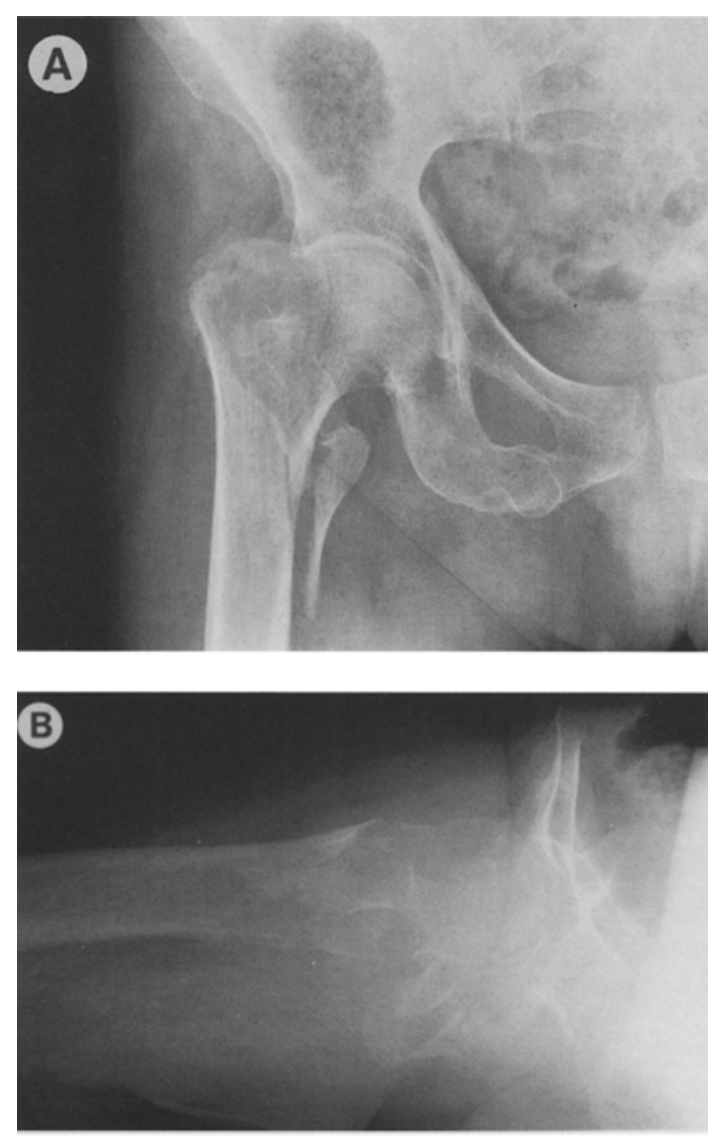

Fig 5. An intertrochanteric fracture. The wide latitude of contrast in the lateral view provides information of alignment from the femoral head to the proximal shaft. (A) Anteroposterior view: $L=2.0 ; G=1.1, J, 0.6,+0.2 ; R=8, R, 1.0$. (B) Lateral view: $L=2.3 ; G=1.3, D, 1.6,+0.8 ; R=5, R, 0.5$.

mately $4.5 \mathrm{lp} / \mathrm{mm}$ of high-contrast resolution. Figures 1 and 2 show the high resolution achievable.

\section{USE OF DR WITH IMAGE REPROCESSING TO PROVIDE A MORE OPTIMAL IMAGE}

In some cases, the initial image processing is not optimal because of differences in patient size or shape compared with the standard for which the algorithm settings were selected. In these instances, repeat radiographs can often be avoided by reprocessing the digital information.

Figure 3, A and B, show the ability of image reprocessing to better demonstrate the posterior elements of the spine in a patient with spondylolysis and spondylolisthesis.

Figure 4, A and B, show that the artifact surrounding metal appliances can be much decreased by changing the kernel size used for unsharp masking, in this case reducing it from a (frequency) rank number (RN) of 5 to a $\mathrm{RN}$ of 8 .

\section{ADJUSTING RANGE OF CONTRAST}

Adjusting the range of contrast can improve the visibility of structures. Certain radiographic views such as true lateral views of the hip, base of skull views, zygomatic arch views, and nasal bone views can be quite difficult to obtain because of the variability of densities present in the final image. Adjusting the range of contrast or obtaining two different imaging-processing settings can improve the visibility of structures.

Figure 5, A and B, show better than usual visualization of this intertrochanteric fracture on the true lateral view of the hip. This results from the relatively low-contrast image resulting from the higher latitude value of the image.

\section{REPROCESSING OF IMAGES TO OBTAIN ADDITIONAL INFORMATION}

Sometimes a radiographic image will suggest that an additional finding or disease may be

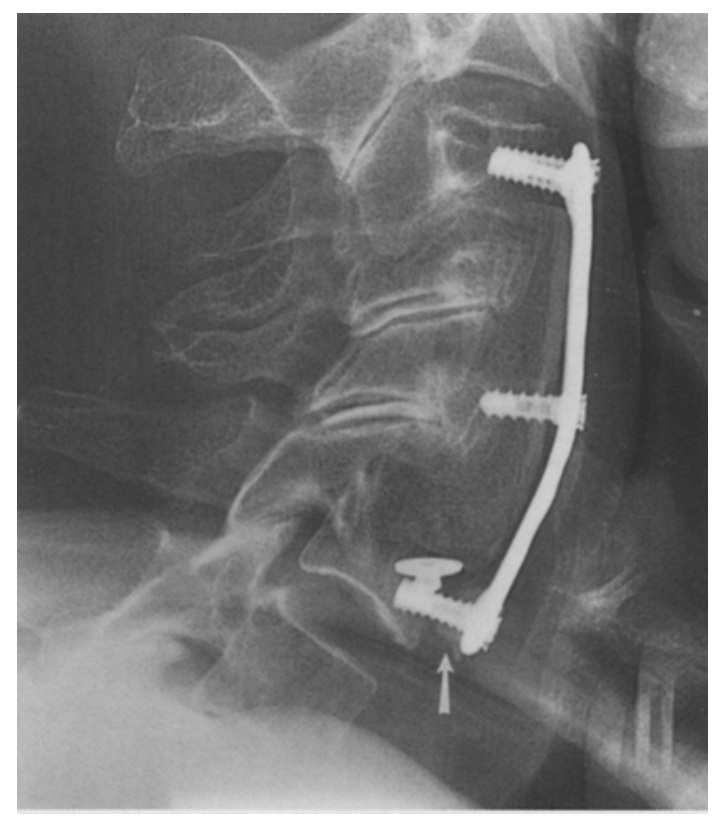

Fig 6. Lateral cervical spine. A small amount of methyl methacrylate can be seen surrounding the screw (arrow). This was used to replace bone that broke off at the time of the surgery. $G=0.9,0,0.6,+0.5 ; R=9, T, 10$ 
present. In these cases, additional image processing may allow improved diagnosis to be made because of the additional information.

In Figure 6, this reprocessed image shows that there is displacement of the sixth cervical vertebra on the seventh. Reprocessing the image showed the bone margins more clearly and showed a small plug of methacrylate that had been used to fill in a gap around the screw and had pulled out of the bone along with the screw.

\section{CONCLUSION}

Digital radiography properly optimized and properly used provides better image quality than conventional screen-film radiography. It provides sufficient resolution, high consistency of image quality, and the ability to reprocess images for better visualization of information. We are proceeding with our plans to completely replace conventional screen-film radiography with digital radiography. We will be entering all of these images into our IMAC system.

\section{REFERENCES}

1. Smith DV: Personal communications, February 1994.

2. Wilson AJ, Murphy WA, Monsees BS, et al: Photostimulable phosphor digital radiography of the extremities: Diagnostic accuracy compared with conventional radiography. AJR 157:533-538, 1991

3. Murphey MD: Digital skeletal radiography: Spatial resolution requirements for detection of subperiosteal resorption. AJR 152:541-546, 1989

4. Bramble JM, Murphey MD: Letter to the Editor of Radiology. 177:587-588, 1990

5. Kreipke DL, Silver DI, Tarver RD, et al: Readability of cervical spine imaging: Digital versus film/screen radiographs. Comput Med Imaging Graphics 14:119-125, 1991

6. Nelson MC, Pe E, Freedman MT, et al: Image processing in musculoskeletal digital radiography: A comparison of the AGFA and Fuji bone algorithms. SPIE Med Imaging 2167:854-867, 1994

7. Nelson MC, Pe E, Freedman MT, et al: Image processing in musculoskeletal digital radiography. SPIE Med Imaging 2167:672-681, 1994

8. Freedman MT, Mun SK, Pe E, et al: Image Optimization on the Fuji AC-1. SPIE Med Imaging 1898:480-502, 1993 